\title{
ALGUNAS ANOTACIONES ACERCA DE LA EDUCACIÓN SEXUAL
}

\author{
Marga Sánchez y Trinidad Simó
}

La represión en materia de sexualidad ha sido sustituida en los últimos tiempos por una cierta apertura. En este sentido se han publicado algunos libros sobre el tema y hay intentos de incluir la educación sexual dentro de la educación general. Sin embargo, estos intentos chocan con el desconcierto de los padres y con la oposición de diversos sectores sociales. Además, lo que es más importante, estos intentos perpetúan todos los mitos tradicionales sobre la sexualidad femenina, con lo cual no contribuyen al desarrollo de una verdadera liberación sexual de las mujeres, ni a un cambio sobre las viejas ideas de lo que es la sexualidad. 
«Mamá, Juanito tiene pilila y yo, ¿qué tengo?» «Tú nada, hija; de eso no se habla.»

Esta frase tan conocida es para nosotras la que mejor resume el trato dado oficialmente a la sexualidad en estos cuarenta últimos años. Trato basado principalmente en dos aspectos:

a) Omisión del sexo fuera del matrimonio, fundamentalmente el sexo femenino al que se considera justificado, y se llega a pensar que satisfecho con la reproducción.

b) Discriminación absoluta, considerada como natural entre niños y niñas, que llevará a marcar unas pautas estereotipadas difícilmente superables en la vida adulta.

Estos dos aspectos nos llevaron en su día a hacer un cursillo de Educación Sexual en la «I Escola d'Estiu al País Valencià». De él volvemos a retomar, en este artículo, muchas de las ideas alli discutidas.

Durante los últimos cuarenta años la educación sexual en España ha sido prácticamente nula si la consideramos tal como ha aparecido o se ha impartido en otros países. Ahora bien, no podemos negar que ha existido una determinada actitud hacia la sexualidad, y que por lo tanto se puede hablar de la existencia de una muy concreta educación sexual, que ha sido la oficial, dirigida por la Iglesia Católica, y que se ha dado fundamentalmente en escuelas y en el núcleo familiar.

Durante mucho tiempo los colegios religiosos marcaron la pauta en cuanto a la sexualidad. Las órdenes religiosas fueron predominantes en los colegios privados y muchos de nuestros ciudadanos han sufrido su moral rígida y férrea.

En esta «educación» el sexo ha sido considerado como básicamente negativo: fuente de placer (no puede negarse) pero también fuente de perdición y perversión. Sólo ha sido aceptado, encauzado y tolerado dentro del matrimonio, e incluso muchas veces se explicitaba que para dar 
«hijos para el cielo». Esta norma iba más directamente dirigida a las mujeres, ya que se consideraba que los hombres tenían necesidades sexuales mucho más perentorias y que por tanto había que perdonarles una mayor libertad. Dentro de este orden de cosas pecaminosas había que evitar el conocimiento del propio cuerpo (productor de placer) y todas las prácticas e informaciones que conducen a ello. Las relaciones sexuales, puesto que eran tema tabú, tampoco podían ser abordadas. Y de la misma manera se silenciaban las consecuencias que de ellas pueden derivar como, por ejemplo, el embarazo, con el consiguiente perjuicio que recaía sobre la mujer...

En todo este proceso general de represión y de diferenciación sexual segín los sexos, eran las niñas las que llevaban siempre la peor parte, puesto que con ellas siempre hubo aquella especial severidad. Al esquema hecho de que «tienen menos necesidades» venía a sumarse aquel otro que tantas causas para el cielo ha ganado: «las niñas son puras», son «ángeles virtuosos», teniendo todos estos calificativos un trasfondo básicamente sexual. A este respecto la Iglesia Católica, ya a nivel europeo y no solamente español, creyó oportuno reforzar estas creencias creando mitos femeninos que consolidaran conductas de abstencionismo sexual, hasta la muerte si fuera preciso... Y. María Goretti fue canonizada.

¿Qué consecuencias directas resultaban? ¿Qué actitud o disponibilidad se creaba de cara a la vida sexual de la persona? En un primer lugar, la ausencia de información científica dejaba a los niños con una curiosidad que tenían que saciar en otras partes. Y, a la joven, la dejaba absolutamente indefensa frente a la fortuita posibilidad de embarazo, lo cual cuando menos le creaba una actitud de miedo, de prevención, de prudencia constantes y, a la larga, de rechazo y de distanciamiento.

En la niña, pues, y en términos generales, una actitud básica: pasividad, aceptación resignada, idea de servicio en el matrimonio y prevención frente a la sexualidad. Y en el niño, aunque bien es verdad que también se le creaba esta actitud general de distanciamiento, al ser potenciada mucho más su sexualidad - aunque sólo fuera por los caminos de la tolerancia-, creaba en él la sensación de dominio y agresividad con tendencia a pensar en la mujer en términos de objeto. En cualquier caso, esta educación reforzaba una falta de respeto y de comunicación al disociar de esta manera los papeles masculino y femenino, de la misma manera que al condenar la sexualidad como algo pecaminoso la condenaba, en el campo masculino sobre todo, al reino de la picardía y de las transgresiones morales.

En definitiva, actitudes ambiguas y contradictorias muy difíciles de ser superadas nunca, en las que la mujer sobre todo salía básicamente per- 
diendo: «aquella educación» castraba su espontaneidad e iniciativa erótica; con el agravante de que esto, muchas veces, se convertía, en el futuro, en algo irreversible.

\section{¿Un cambio en la educación? ¿Una apertura?}

Hemos visto hasta qué punto no puede mantenerse, porque no corresponde a la realidad, aquello de que aquí, en este país, no se ha impartido enseñanza sobre la sexualidad $o$, dicho de otro modo, no ha habido educación sexual. Muy al contrario, como acabamos de ver, ésta se ha programado de una manera muy estricta, aunque fundamentalmente se haya ceñido a su parte negativa y en la orientación antes comentada.

¿Podemos, pues, definir todo este período como el de una educación sexual represiva, represiva en términos generales, si bien más abierta y permisiva para el niño que para la niña? Así parece ser.

Sin embargo, a partir de los últimos años una cierta «mano ancha» parece querer reemplazar a la antigua enseñanza severa. Pues es cierto que a nivel real, a nivel de la calle, el panorama ha cambiado desde hace unos años. Una mayor información general y cultural llega a España. Se editan y traducen libros antes impensados; se proyectan películas hasta ahora prohibidas; y las costumbres van cambiando empujadas por una moral sexual mucho más abierta. Lo que los adultos jamás se permitieron a sí mismos, al menos a la luz del día y con carácter de normalidad, los jóvenes lo practican en su propia conducta. El vocabulario sobre las cuestiones sexuales, mucho más libre, no hace más que demostrar el cambio que se está produciendo.

De manera que el panorama anteriormente descrito del más completo oscurantismo sobre educación sexual es absolutamente irreproducible. $\mathrm{Y}$ de esto se dan perfecta cuenta padres y maestros, pues a menudo se sienten sobrepasados por los hijos. Las preguntas o las actitudes de éstos van mucho más allá de lo que los padres podían esperar; y ante la curiosidad del hijo y de la hija, los padres o maestros, gran parte de las veces, sólo saben contestar con evasivas. Pero en cualquier caso éstos son conscientes que hay todo un silencio que no saben romper y que es necesario que, de alguna manera, se haga.

Ante esta situación de permisividad respecto a las costumbres y a la vida real cotidiana por una parte (permisividad que tanto repercute en la mentalidad del niño), y de desconcierto por parte de la mayoría de los educadores, la «apertura» ha comenzado a llegar. 
El cambio se ha producido en términos aislados. Ciertos centros, algunos profesores, recogiendo la inquietud general, han comenzado a cuestionarse la absoluta falta de información sobre el terreno sexual: si ésta podría seguir manteniéndose y hasta qué punto se puede pensar en otra orientación.

Algunos libros de talante avanzado con respecto a lo que hasta ahora se conocía han sido editados. Estos libros van dirigidos a los niños o bien a «padres vergonzosos», como es el caso del libro de la Editorial Grijalbo De dónde venimos, y pretenden suplir el silencio o la mistificación que se ha mantenido hasta ahora sobre preguntas básicas y concretas: de dónde y cómo vienen los niños; cómo se realiza el coito; cuáles son las diferencias corporales y biológicas entre el hombre y la mujer. Éstos parecen ser los tres grandes interrogantes.

Qué duda cabe que estos libros, a nivel educativo, significan un cambio real que tiene que repercutir en romper viejos tabús o ampliar los conocimientos sobre esta materia. Al menos alientan a padres y maestros «vergonzosos» (como decía aquel libro) para poder explicar lo que viene a ser el abc de la sexualidad. Pues aunque parezca que la situación en los colegios debiera ser distinta, al menos al juzgar por la mayor abundancia de desnudos en medios de difusión visual como cine y revistas de erotismo, etcétera (una de sus consecuencias sería aquello, tan específicamente español, que se ha venido en llamar destape), en realidad no ha variado demasiado.

A este respecto son recientes los casos de profesores sancionados. Las asociaciones de padres, imbuidas todavía de una especie de responsabilidad por salvar la ignorancia de los hijos, se han mostrado particularmente severas últimamente. En Gerona, una joven maestra fue llevada a juicio por haber enseñado y explicado el libro, ya mencionado, de la Editorial Grijalbo. En Valencia, un joven profesor corre el riesgo de denuncia por haber querido enseñar a los jóvenes los medios anticonceptivos que en la actualidad existen.

La pregunta sería si realmente podemos hablar de apertura. Y qué entendemos por ella. Los ejemplos de denuncias antes comentados, llevados incluso a nivel de prensa nacional (al menos el primero), nos hacen comprender que ésta es nula. Que si bien hay intentos por parte de personas, estos intentos se hacen aislados mientras que el clima general no tolera, todavía, exposiciones francas y desmitificadoras que hablen, al menos, de aquellos tres puntos concretos: dónde y cómo nacen los hijos, diferencias corporales y biológicas entre hombre y mujer, y cómo y qué es el coito. Es indudable que aquí, con estas explicaciones, no terminatía el nivel de información necesario, y sobre todo no sería suficiente para 
contribuir a crear un clima favorable a una sexualidad abierta, pero sí que, de darse esto, podía hablarse, ya, de una cierta apertura real.

A otro nivel, convendría preguntarse en qué dirección es proyectada la sexualidad en estos libros que se han editado y que, al menos aparentemente, van dirigidos a los niños. En todos ellos nos encontramos el mismo enfoque. 1. Las relaciones sexuales son descritas en el matrimonio y con la clara finalidad de tener. hijos. 2. Como consecuencia del planteamiento anterior todo lo concerniente al placer es o bien anulado o bien reducido al máximo. Incluso puede ser que ni siquiera éste se mencione - bien, en el caso de mencionatse, la pobreza y el mecanicismo de la explicación salta inmediatamente a la vista. $\mathrm{Y}$ así, con este enfoque que oculta, más o menos claramente, el placer, no hace falta mencionar órganos como el clítoris, ni prácticas como la masturbación, a pesar de que todos sabemos que son prácticas absolutamente generalizadas que a menudo llegan a ser un auténtico problema en los jóvenes. Y 3. La sexualidad es entendida en una dimensión de fuerzas o de actitudes distintas entre el hombre y la mujer. Así, es el hombre quien actúa, quien se proyecta, quien toma la iniciativa amorosa $y$, al final, quien se introduce en la mujer. Es él quien realiza la acción amorosa. A este respecto, nos parece aclarador del libro ¿De dónde venimos? lo que ocurre en el momento del coito: el pene «se hace mucho más grande porque tiene muchísimo trabajo que hacer».

Indudablemente, en estos textos o libros los papeles o roles sexuales tradicionales, a pesar de esta apertura, no han conseguido variar. La actitud de la mujer continúa siendo pasiva (aunque explícitamente no se diga, lo cual es peor, pues quiere decir que es algo no cuestionado y absolutamente al uso). Pero existe un momento de excepción respecto a su pasividad. Un momento muy concreto: el hijo nace. Es entonces, y sólo entonces, cuando la mujer, en su nuevo papel de madre, toma la iniciativa. Todo esto puede verse aunque con mecanismos muy sutiles. Por ejemplo, en el libro Aviat seré un adolescent de Frederic Boix, todo el contexto está descrito en el término clásico en el cual, al hablar de la pareja, se menciona antes el sexo masculino. Así niño y niña, padre y madre, excepto cuando el hijo nace. En ese momento, al oir el llanto del niño, el autor invierte el orden: «La mare, el pare, els metges es posen molt contents»...

Analizando todo esto, viendo la hostilidad de gran parte de los padres frente a los intentos de información o educación sexual que proponen algunos maestros, observando las reservas de los propios centros al respecto y ante la resistencia y pasividad general es indudable que no podemos hablar de una real apertura en la educación. $Y$ aquella mayor permisividad de la que hablábamos al principio no parece corresponder a 
los resultados de un planteamiento serio. La «mano ancha», pues, es sćlo la típica tolerancia de quien se ve sobrepasado por los acontecimientos y no sabe qué actitud adoptar frente a ellos.

En definitiva, el panorama educacional ha cambiado poco y parece corresponder a atajar males mayores y retener costumbres, aunque bajo la apariencia de una mayor modernidad plasmada en una mayor tolerancia.

La educación de los niños continúa en el mismo puesto. Una curiosidad absolutamente lícita aunque nunca saciada, ni siquiera en lo más básico, y que tiene que buscar las respuestas en puntos alejados de padres y maestros. Porque, en términos reales, la sexualidad, en la escuela y en el hogar, continúa viéndose como un mal. Un mal que hay que tolerar $y$ que hay que encauzar.

Y continúa siendo la niña, la joven, la mujer, la que sale perdiendo ahora como antes. A aquellas diferencias sexuales adscritas a determinados roles rígidos y esquemáticos cuya transgresión era en un tiempo castigada incluso con medidas extremas como la muerte, emparedamiento, reclusión de por vida en conventos, etcétera, si bien este panorama de dureza no se reproduce hoy, sí que se puede hablar, en cambio, de una actitud social general de rechazo que queda refrendada y bendecida por la legislación vigente, tan desfasada incluso con nuestra propia realidad social. Legislación donde el adulterio y el uso de anticonceptivos continúan siendo penados con el agravante de que sólo la mujer es la considerada adúltera y sólo la mujer es la que toma anticonceptivos. En definitiva, la mujer fue soporte de la familia cristiana pero continúa siéndolo ahora. La virginidad, la pureza, el sacrificio, la abnegación fueron y son las virtudes de la mujer española. $Y$ aunque hoy no se exige tanto se continúa pidiendo "cosas a cambio». Ésta es la cuestión: se le siguen pidiendo cosas, se le piden desde que nace, que sea dócil, juiciosa, con pocas necesidades, siempre comedida, siempre poniéndose límites. $Y$ en estos límites colaboran todos, padres, maestros, familia, aunque si bien no siempre explícitamente, pero sí con cariño, con sonrisas, con dulces insinuaciones, consiguiendo que al final haga y viva como cosa suya su propia limitación. Éste es el gran chantaje a que se le somete: cariño a cambio de dejarse proteger, como el débil, y estar siempre dispuesta a hacer la vida agradable a todos los de su alrededor. Ésta es su tarea principal.

Los siglos xvin y primera mitad del xIx constituyeron la gran época de la educación sexual por el temor. Testimonios médicos, religiosos, et- 
cétera, pregonaban las enfermedades más espantosas acerca de la práctica de la masturbación.

Los moralistas, paralelamente a responder a la curiosidad de la juventud con verdades aproximadas, manifestaban el deseo de formar un adulto para quien el otro sexo no existiera, y no sólo eso, sino que para él el propio sexo fuera olvidado.

Pero desde funes del XIx se inauguró el estudio de la sexualidad. $\mathrm{Y}$ las ideas que han aportado Krafft Ebening y Freud no podrán ya dejarse de lado.

En efecto, los estudios de Frreud y de toda la escuela psicoanalítica sobre sexualidad infantil acabaron con las ideas arraigadas hasta entonces, como aquélla de que la sexualidad no empezaba hasta los 14 años. Ahora sabemos que la sexualidad no es algo que aparece en la pubertad, sino que desde el nacimiento el niño llega al mundo con su sexualidad. Es suficiente observar su comportamiento para darse cuenta de ello: chupar, mamar, evacuar, etcétera, son todas cosas cargadas de interés para el bebé; todos estos actos sirven para el conocimiento del niño y de su entorno, y sólo podrá llegar a conocerlo en la medida en que él pueda conocerse y considerarse distinto de lo que le rodea.

Pero a pesar de todos estos conocimientos, y quizá precisamente porque no son suficientemente conocidos, el adulto vive la educación sexual de los hijos con ambigüedad en el mejor de los casos. Por ejemplo, el niño explora su cuerpo y sus órganos genitales entran en esa exploración. Ante esta actitud infantil muchos padres reaccionan negativamente y apartan las manos de sus hijos de los órganos genitales; serán padres que más tarde no contestarán a las preguntas de sus hijos o darán respuestas distorsionadas a sus inquietudes sexuales, pues para considerar la sexualidad infantil, es necesario que los padres se mantengan objetivos y vayan más allá de sus propios fantasmas producidos por una determinada educación.

Otras veces el adulto pone buena voluntad y habla del tema una vez con el niño, pero de todas maneras, debido a su educación y temor a la sexualidad, no comprende que no se trata de hablar una vez, sino que lo importante es su actitud ante la vida.

Respecto a la educación sexual en las escuelas continúan existiendo varios enigmas: todavía no está claro si debe impartirse en las escuelas, si debe existir un profesor especializado en esta materia, o bien hasta qué punto es conveniente una educación o sólo y meramente una información. Hay países, como por ejemplo EE.UU., en los que la educación sexual es impartida como materia específica, con información sobre las partes del cuerpo y sus funciones; esta asıgnatura, puesto que así puede 
llamarse, está dada por un profesor de Ciencias Naturales y por un profesor especializado que es el encargado de dirigir charlas, debates, películas, etcétera. Al mismo tiempo se va recogiendo todo un material que se ha ido construyendo con y para los alumnos. Las charlas suelen tratar del embarazo, parto, higiene sexual, acto sexual, etcétera. Finalmente se van graduando según las edades.

Otros países menos avanzados en sus propuestas han intentado, al menos, ver cuál sería la reacción de padres y enseñantes en el caso de introducirse la educación sexual en las escuelas. Éste es el caso de Francia e Inglaterra. En el año 1947, en Francia, se intentó estudiar en qué medida y bajo qué forma una educación sexual podría introducirse en los establecimientos de Educación Pública. Y por los mismos años, en Inglaterra, una circular de 1943 invitaba a las autoridades locales de Educación a hacer lo necesario para instalar la educación sexual en las escuelas. Sin embargo, la enseñanza en materia sexual todavía no ha sido introducida con carácter general y obligatorio. No obstante, en Suecia, la educación sexual es materia obligatoria desde los 15 años más o menos. En las escuelas hay tres ciclos desde primaria hasta la superior (de 13 a 16 años). No es una materia escolar como tal. Durante los ciclos primero y medio, es impartida por el profesor principal y en los niveles siguientes tiene que ser integrada en las Ciencias Naturales, en la instrucción cívica, en la instrucción social y en el conocimiento de las religiones.

Dejando aparte el gran paso que supone el intentar incluit la educación sexual en la escuela, tememos que ésta se quede como una parcela de Ia educación, cuando la sexualidad no es un apartado de la vida del individuo, ni un reducto que se pueda tratar particularmente y sobre todo aisladamente de otros contextos.

Antes que reducirla a una asignatura hay cosas más perentorias, como puede ser el destruir viejos esquemas pues difícilmente se podrá tener una actitud permisiva y abierta hacia la sexualidad en una escuela autoritaria, por ejemplo, donde todos los papeles están claramente determinados y separados. Y difícilmente se podrá hablat de Educación Sexual cuando todavía se persiste en reproducir y fomentar los roles tradicionales adscritos a las diferencias sexuales.

En este sentido, hemos tomado un ejemplo de un libro de cartas de maestros y niños sobre educación sexual. El libro es de Adler, Qué opinan nuestros bijos de la educación sexual. Reproducimos una carta de un profesor a los padres de una alumna: 
Mi estimada señora:

Me siento complacida de comunicarle que los alumnos de la clase de Educación Sexual II han proclamado a su hija como la estudiante con más posibilidades de éxito.

Felicitaciones.

Esta carta nos hace sacar, por lo menos, dos conclusiones: ¿Qué éxito futuro es el que más o menos se prevé en ella? Nos tememos que sea el tradicional éxito adscrito a la sexualidad femenina, el de la seducción o de saber satisfacer a otro y atraerlo. La niña se aseguró la manera de procurar placer a otros, pero nos cuestionamos si esto le dejará en libertad de realizar el suyo propio. $\mathrm{Y}$ en segundo lugar, ies que es algo a aprender la sexualidad? ¿Es que acaso se pueden establecer criterios de éxito o fracaso? Esto sería tanto como pensar que existe una normativa sexual y que la sexualidad tiene un armazón a su alrededor que es válido.

Está claro que esto es lo que se piensa y es lo que se da en muchos planteamientos sobre educación sexual. Conseguir que nadie se separe de lo previsto, y a menudo esta actitud se refuerza con un halo de cientificidad y de biologismo. Cada uno obtendrá éxito en su papel, el hombre será más hombre y la mujer más mujer, bien separado cada rol para conseguir un todo más adaptado.

Pero en cualquier caso, aunque no se refuercen tanto estos papeles tradicionales, siempre existe, desde el momento en que se da una notmativa, una merma de la sexualidad propia, individual, la que el propio ina:viduo tiene el derecho de crear y de vivir según sus propias opciones.

Encontramos muy aclaradora y saludable la respuesta que los niños de un colegio francés dieron a su profesor de Educación Sexual: «La vida sexual de los alumnos es del dominio privado, no es papel de la escuela el de erigirse en censor.»

Qué duda cabe que setá conveniente dar toda la información que se pueda, pero en ningún caso la sexualidad es cuestión de normas y pautas y clases especiales para aprendetlas; y que, en primer lugar y antes que nada, requerirá una actitud abierta de enseñantes, padres y adultos en general. Pues de nada sirve explicar algo de sexualidad al niño, si a continuación una pregunta o una actitud que se salga de lo previsto nos deja sin respuesta o nos hace recurrir a veladas prohibiciones. Cuando los padres contestan «No preguntes delante de la gente, luego te lo diré», y ese luego no llega nunca.

$Y$ qué duda cabe, también, que es absolutamente necesaria una información científica sin ambigüedades, que cubra aquellas tres preguntas 
básicas ya mencionadas, así como también todo lo referente a la biología, la higiene sexual y la explicación de técnicas anticonceptivas modernas.

Pero todo lo que sobrepase esta información, digamos elemental, mucho nos tememos que no sirva más que para encuadrar la sexualidad en normas, como hemos dicho antes, para reforzar comportamientos tradicionales y para inhibir o desencajar la sexualidad del niño y de la niña. Y ya hemos visto hasta qué punto la sexualidad de la niña queda mermada con este planteamiento y hasta qué punto la del niño resulta potenciada en términos de agresividad y de dominio.

Dicho en otros términos, consideramos absolutamente necesaria, con una necesidad dramáticamente perentoria, la información sexual, hasta el punto de juzgarla como un derecho inalienable que tiene el niño, pero no opinamos de la misma manera respecto a lo que podría llamarse educación.

Si dejáramos a los niños y a los jóvenes que fueran ellos mismos quienes se cuestionaran, a medida que su curiosidad creciera, de una manera natural, y que fueran «educando» ellos mismos «su» sexualidad, se conseguirían unos resultados más ricos y gratificadores para la persona y, a la larga, la sexualidad ocuparía el lugar que debería ocupar: una opción personal que gratifica y que potencia a uno mismo y al otro.

Pero no vivimos en la Arcadia feliz. No vivimos en tierra de iguales. $\mathrm{Y}$ esto lo sabemos mucho más dramáticamente y en profundidad las mujeres. Vivimos en un mundo en el que los roles culturales adscritos a las diferencias sexuales biológicas entre hombre y mujer, dejan a ésta en una actitud de pasividad, ignorancia, sumisión y como objeto de entretenimiento sexual respecto al hombre.

Se impone, pues, que ya que se habla de educación sexual, ésta seà tomada en profundidad. Es decir, no apuntando a técnicas, etcétera, sino a lo que está en su base: a destruir aquellos roles diferenciadores que nada tienen que ver ni con la biología ni con la ciencia, y ni siquiera con nuestra más rutinaria convencionalidad actual. Sólo obedece a una adscripción cultural de vencedores y vencidas.

Urge, pues, como única educación posible, la coeducación. Coeducación que no se reduce a la escolarización mixta o al simple hecho de cohabitar, pues planteada en estos términos tan simples y primarios a menudo sólo ayudan a reforzar diferenciaciones, a evidenciarlas y a exasperar aquellas posturas antagonistas. La coeducación se plantea lo contrario: destruir los prejuicios que dividen y separan los sexos: el uno, el masculino, en términos de opresor; el otro, el femenino, en términos de oprimido. Es sólo desde esta base como concebimos la educación sexual: nada tiene que ver con las técnicas, sólo tiene que ver con la igualdad entre los sexos $y$, por lo tanto, con la libertad. 
Anotaciones acerca de la educación sexual

La educación, pues, pero en la coeducación, que se inscribe en el complejo marco de la educación general, del desarrollo afectivo, ético, moral y psicológico del niño y de la niña. 